\title{
Research on Control System of Installation Environment for 500kV Cable Tunnel Joint
}

\author{
Chuang Wang, Yi Gao, and Wenqing Yang* \\ Guangzhou Power Supply Bureau, Guangdong Power Grid co.,Ltd., Guangzhou, China
}

\begin{abstract}
The environment in the $500 \mathrm{kV}$ cross-linked cable tunnel is bad, which is not conducive to ensuring the joint manufacturing process, and it is easy to cause joint installation defects. A joint installation environmental control system stabilizing the temperature and humidity of the joint installation area and reducing dust particles in the air was designed and developed. A closed space in the joint area was formed by use of sliced inflatable membranes. The integration of refrigeration and air-conditioning technology, air dehumidification technology, air filtration technology and air volume adjustment technology realized temperature, humidity, and cleanliness control of the joint installation area. Stable temperature and humidity, as well as clean air atmosphere can greatly improve the installation quality of high-voltage cable joints in the complex cable tunnel environment, and help reduce the failure rate of joints.
\end{abstract}

\section{Induction}

In order to make full use of the urban ground space, improve the reliability of urban power supply as much as possible, and beautify the urban environment, the current ultra-high voltage cables in large cities usually use underground work tunnels instead of overhead lines. Due to the long distance of the cable tunnel, the complex terrain, crisscrossing each other, and the large number of cables, the working environment in the tunnel is extremely complicated. The temperature and humidity in the tunnel change greatly with the seasons. The relative humidity of the underground tunnel can exceed $100 \%$ in summer. Moreover, the infrastructure construction in the tunnel also has an impact on the environment in the tunnel, resulting in a relatively large dust concentration and air humidity in the tunnel. The manufacturing process of cable joints is complicated, using many tools. And the construction period is long. During the joint manufacturing process, it is inevitable that the joint processing interface will absorb moisture and adhere to dust particles. Temperature changes will cause uneven heating of the components of the cable joint, resulting in installation errors [1-7].

With the development of industrial technology, especially in the installation process of GIS equipment in UHV projects, strict dust-proof measures have been implemented to ensure high cleanliness by controlling the "dust level" of the external environment. It improves the installation quality of GIS equipment and plays an important role in the later safe and stable operation. With reference to the technical practice and experience of GIS equipment installation, a controllable tent was used to physically isolate the joint area at the installation site of the cable joint, which initially realized the environmental control of the joint installation environment [8-12].

In order to achieve centralized and precise control of ambient air parameters in the installation area of cable joints with voltage levels of $500 \mathrm{kV}$ and above, it is necessary to design an environmental equipment system and corresponding environmental monitoring systems to ensure the installation quality of cable joints. Under the premise of meeting national standards, quantitative control of the temperature, humidity and cleanliness of the cable joint environment will greatly improve the installation reliability and work efficiency of the installation of cross-linked cable joints. It can also reduce future maintenance workload and maintenance costs. At the same time, as a kind of technical reserve, it can promote the improvement of joint technology and achieve good economic benefits.

\section{Joint installation environment characteristics and design goals}

\subsection{Environmental structural features of $500 \mathrm{kV}$ cable tunnel}

The depth of the $500 \mathrm{kV}$ cable tunnel in this article is between $10 \mathrm{~m}$ and $20 \mathrm{~m}$, and the total length of the tunnel is more than ten kilometers. The tunnel is made of monolithic concrete and the cross-section is a closed circle with a diameter of $3.5 \mathrm{~m}$. There is a $600 \mathrm{~mm}$ diameter work well every $1 \mathrm{~km}$. Beside the wellhead, there is a passageway for personnel and access stairs to the inside of the tunnel. The width of the tunnel bottom is about $1 \mathrm{~m}$. Two sets of cables are installed up and

\footnotetext{
Wenqing Yang: 545704526@qq.com
} 
down on both sides of the tunnel. The structural dimensions of the tunnel are shown in Fig. 1.

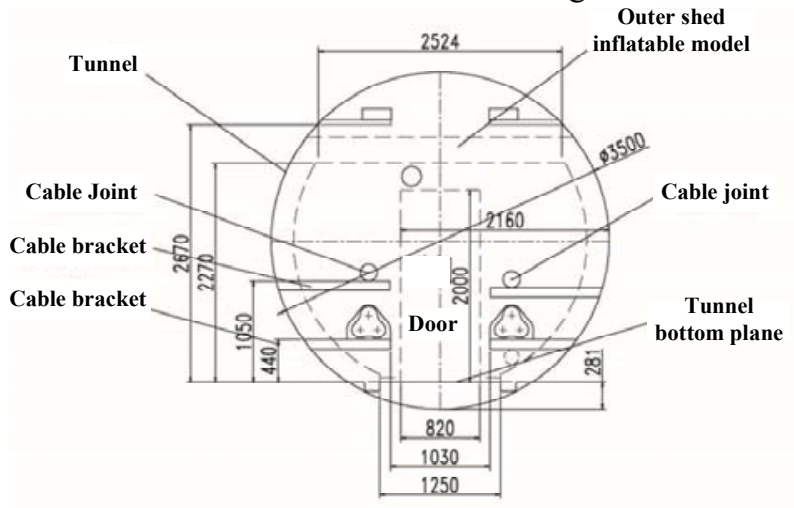

Fig. 1. Schematic diagram of $500 \mathrm{kV}$ cable tunnel section.

\subsection{Arrangement of $500 \mathrm{kV}$ cable joints}

The distance between each group of $500 \mathrm{kV}$ cable joints in the tunnel is $700-800 \mathrm{~m}$, and the same group of cable joints are separated by $10 \mathrm{~m}$ in the axial direction of the tunnel.

Therefore, the length of the tunnel occupied by each joint point is $30 \mathrm{~m}$ (the length of the operating space for each phase joint installation is $10 \mathrm{~m}$ ). When installing the joint, the same group of cable joints must be installed at the same time. The joint layout is shown in Fig. 2.

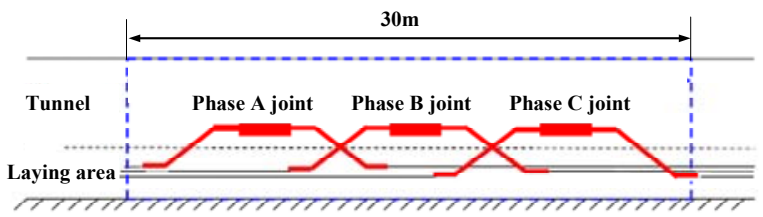

Fig. 2. Schematic diagram of cable joint area layout.

\subsection{Design goals of the joint installation environment system}

In order to ensure a good working environment for the installation of cable joints, according to the actual working conditions of the environment of the crosslinked cable joints, referring to the joint process requirements of the cross-linked cable, and in accordance with the relevant standards of the clean plant purification project, a set of cable connection environmental system engineering had been developed.

The temperature, humidity, and cleanliness of the joint installation environment engineering needs to meet the requirements, that is, the temperature is not more than $28^{\circ} \mathrm{C}$, the humidity is not more than $75 \%$, and the cleanliness of the local working area reaches level 9 (the amount of dust in the particle size of $1.0 \mu \mathrm{m}$ is not more than $8320 \mathrm{pc} / \mathrm{dm} 3$ ) standard requirement. At the same time, it is also necessary to provide construction personnel with a convenient, fast and safe joint installation work platform, with a safe lighting and ventilation system to ensure the safety of the tunnel construction. Centralized intelligent control of the entire system is needed to monitor the enclosed environment of the tunnel joint area in real time.

\section{Design of Environmental Control System for 500kV Cable Joint Installation}

To achieve the design requirements of the working environment, it is necessary to design a multi-functional integrated and modularly assembled environmental complete set of equipment with functions including temperature and humidity control, dust removal and cleaning, lighting, ventilation systems, as well as intelligent control software programs and closed environment monitoring of the joint installation area system. The working area was closed with an air model designed according to the shape of the inner wall of the tunnel, and lighting and ventilation ducts were integrated on the air model.

\subsection{Air handling equipment for joint environmental control system}

The $500 \mathrm{kV}$ cable joint installation environment system includes 7 modules: primary filter section, surface cooling section, fan, dehumidification, re-venting, electrical control, and public foundation. It is compatible with technologies such as air conditioning and heating, dehumidification, air filtration, intelligent automatic control, pressure-maintaining inflatable membrane, etc., which can accurately and efficiently ensure the realization of various indicators, with dense technology, high integration, and complex control. The function layout is shown in Fig. 3.

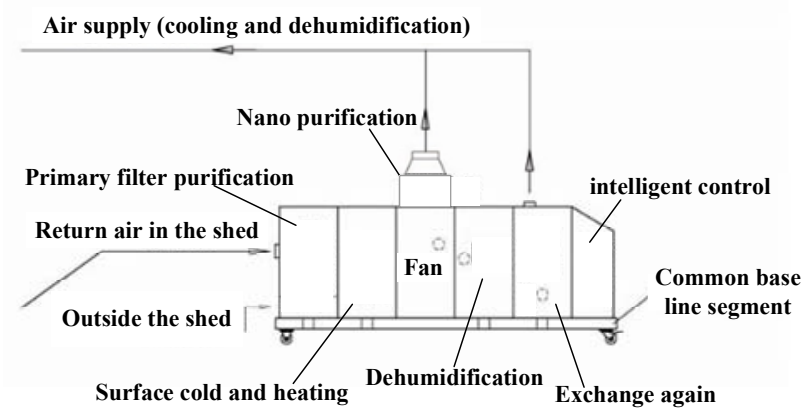

Fig. 3. System function composition of $500 \mathrm{kV}$ connector installation environment.

(1) Primary-efficiency filtration and purification module. Used for the return air and fresh air filtration in the work area, the size is $420 * 420 * 800 \mathrm{~mm}$. An electronic precipitator filter and primary effect filter are installed to filter particles larger than $10 \mu \mathrm{m}$ in the air with a filtration efficiency of $90 \%$.

(2) Surface cooling and heating module. It is used for cooling, dehumidification and heating of the work area, the size is $420 * 420 * 800 \mathrm{~mm}$. Refrigeration compressor, evaporator, condenser, expansion valve and cold medium are installed.

(3) Fan high-efficiency filter air supply module. The clean air filtered by the high-efficiency filter is sent to 
the working area through the fan, the size is $420 * 420 * 1200 \mathrm{~mm}$. This module is equipped with blower and high efficiency filter. The high efficiency filter mainly filters particles larger than $0.5 \mu \mathrm{m}$ in the air, with a filtration efficiency of $99.99 \%$.

(4) Dehumidification runner module. The air is sucked out of moisture through the moisture absorption wheel, and low humidity air is discharged. The size is $420 * 420 * 800 \mathrm{~mm}$. The module is equipped with a moisture-absorbing runner and a reducer.

(5) Dehumidification and air exchange module. It is used for the regeneration of the moisture-absorbing runner to ensure the continuous dehumidification of the moisture-absorbing runner, the size is $420 * 420 * 800 \mathrm{~mm}$. The module is equipped with regenerative exhaust fan, regenerative electric heating.

(6) Intelligent control module. It can realize automatic control and operation of the above modules, and monitor the operation of the equipment. The size is $420 * 420 * 800 \mathrm{~mm}$. It is equipped with electrical automatic control components and operates the touch screen.

(7) Common basic wiring segment module. The above modules are installed on this module to undertake the control connection of the other 6 modules. The module is equipped with the automatic control connection port of each module.

\subsection{Closed gas model technology of environmental control system}

Using inflatable air mold technology, an air mold closed system is made according to the shape of the tunnel, and the tunnel joint area is sealed with an air mold. After the inflatable model is inflated, the air outside the area can be blocked from entering, and it can also prevent tunnel dew from entering the joint area. The joint area is isolated from other spaces in the tunnel. The uninflated inflatable material is soft and easy to ship and reuse.

\subsubsection{Inflatable materials}

The closed inflatable mold used in this project discards the integral inflatable membrane that is difficult to manufacture and is difficult to repair when it fails. A split inflatable membrane is used. The single-piece inflatable membrane is small in size and easy to process and manufacture, simple in installation technology, and extremely repairable. There are natural weaknesses in the overlap area of the single inflatable membrane, and its airtightness is ensured by the inflatable material and the overlap process.

The gas model adopts PTFE membrane whose fireproof performance meets the national fireproof technical regulations. The performance parameters are shown in Table 1. PTFE membrane is made of ultra-fine glass fiber fabric coated with polytetrafluoroethylene resin. PTFE membrane material has the advantages of durability, oil stain resistance, fire resistance and antifouling properties. The PTFE inflatable fabric forms an inflatable channel between the two layers of fabric through a special process. All the seams of the channel are overlapped in full size, and the reinforcement tape is used to strengthen the protection in the overlap seam to ensure high air tightness.

Table 1. Technical parameters of inflatable fabrics.

\begin{tabular}{|c|l|l|}
\hline Item & Testing method & \multicolumn{1}{|c|}{ Value } \\
\hline Support cloth EC3 & DIN 60001 & EC3 \\
\hline Greycloth-Weight & DIN ISO 9354 & $450 \mathrm{~g} / \mathrm{m}^{2}$ \\
\hline Type of coating & $/$ & PTFE \\
\hline Total weight & DIN EN ISO & $1100 \mathrm{~m}^{2}$ \\
\hline Tensile strength & DIN 53354 & $6500 / 6000 \mathrm{~N} / 5 \mathrm{~cm}$ \\
\hline Tear strength & DIN53363 & $800 / 650 \mathrm{~N}$ \\
\hline Transmission & DIN5036 & $12 \%$ \\
\hline Flame retardant & DIN 4102 & A2 \\
\hline Thermal conductivity & $/$ & $0.0865 \mathrm{~W} /(\mathrm{m} . \mathrm{K})$ \\
\hline
\end{tabular}

\subsubsection{Air film shape}

The shape of the gas model is designed according to the terrain of the tunnel and the complexity of the installation environment of the cable joint. On the one hand, it isolates the internal and external environments when the cable joint is installed, preventing the internal and external environment temperature, humidity, and cleanliness from interfering with each other. On the other hand, it ensures sufficient strength and facilitates disassembly and installation. In addition, the inflatable cavity of the gas model can also be used as an insulation wall to reduce the energy required for cooling the work area.

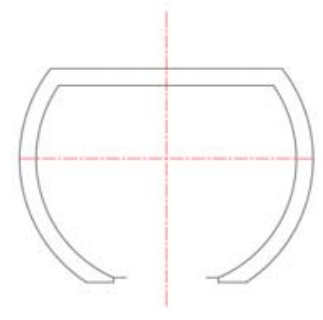

arched air mold

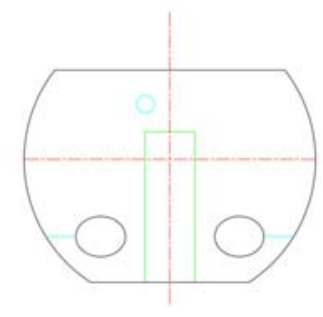

partition air mold
Fig. 4. Schematic diagram of arched air mold and partition air mold.

The arched air mold and partition air mold designed according to the shape of $500 \mathrm{kV}$ cable tunnel were adopted to isolate the environment of the tunnel, as shown in Fig. 4. Arched air mold: Double-layer circular arched air molds are used along the tunnel wall on both sides of the tunnel in the radial direction of the working area (the overall shape of the air mold is a combination of multiple single arched air molds along the tunnel axis). Partition air mold: the working area tunnel at both ends of the axial direction is closed with a double-layer flat air mold partition (the shape of the air mold is a vertical plane).

\section{Key technologies of environmental control system}


The main functions of the $500 \mathrm{kV}$ cable joint installation environmental control system include temperature control, humidity control and cleanliness control, as shown in Fig. 5. The key technologies of refrigeration and air-conditioning, air dehumidification, air filtration and air volume adjustment are integrated to process the air in the joint installation area through a reasonable integration method to meet the requirements of the environment temperature, humidity, and cleanliness of the joint installation area.

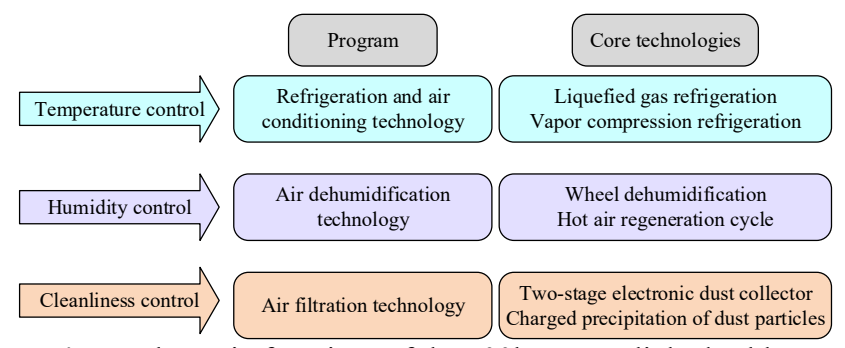

Fig. 5. The main functions of the $500 \mathrm{kV}$ cross-linked cable joint installation environment system.

\subsection{Refrigeration and air conditioning technology}

The system mainly adopts liquid vaporization refrigeration method to adjust the temperature and dehumidify of the closed environment in the form of vapor compression refrigeration. The working principle of vapor compression refrigeration is to make the refrigerant undergo four main thermal processes such as compression, heat release, throttling and heat absorption in thermal equipment such as compressors, condensers, expansion valves and evaporators to complete the refrigeration cycle.

As shown in Fig. 6, due to the transmission of the blower, heat will be absorbed when the air passes through the evaporator, and the temperature of the air will drop. At the same time, the water vapor in the air is condensed into water, which is discharged out of the machine through the drip tray. When the air is circulated in the machine and then sent out, the temperature of the air drops, the moisture in the air continuously decreases, and the relative humidity decreases.

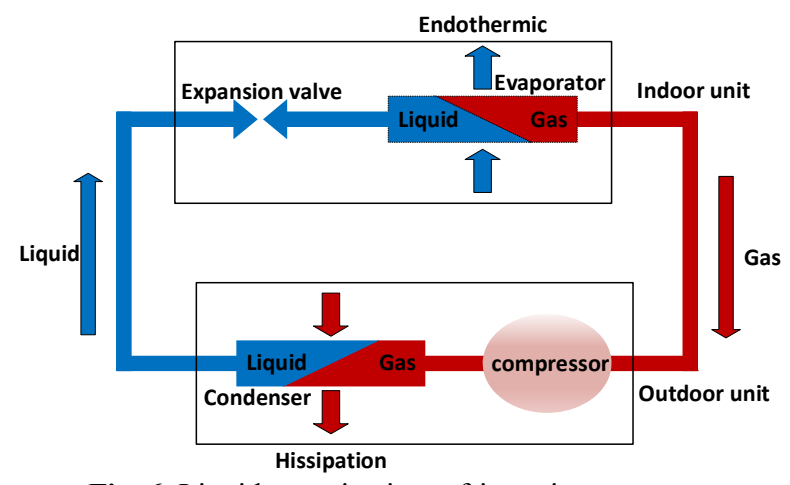

Fig. 6. Liquid vaporization refrigeration process.

\subsection{Air dehumidification technology}

Since the original humidity of the enclosed environment is very high, and the large space of the enclosed environment leads to a large amount of dehumidification. Refrigeration and dehumidification can only remove most of the moisture in the air, and the remaining moisture must be removed by a special dehumidification method.

This system adopts the wheel dehumidification method. The key component of the wheel dehumidifier is the honeycomb drying wheel that absorbs moisture. The runner is made of corrugated medium containing moisture absorbent made of special composite heatresistant material. It can provide a huge surface area for wet air and hygroscopic media to fully contact, thereby greatly improving the dehumidification efficiency.

The principle of the rotary dehumidifier is shown in Fig. 7. The dehumidifying wheel is divided into two sectors by a partition made of a material with high sealing performance. One is the $270^{\circ}$ fan-shaped area at the wet air end; the other is the $90^{\circ}$ fan-shaped area at the regeneration air end. When the humid air enters the $270^{\circ}$ fan-shaped area of the runner, the hygroscopic agent in the runner absorbs water molecules in the air to a saturated state. After being heated, it enters the fan surface of the regeneration zone of the runner. The water molecules in the runner are desorbed and lost in the regeneration air. The dried air is sent to the dry air outlet through the processing fan.

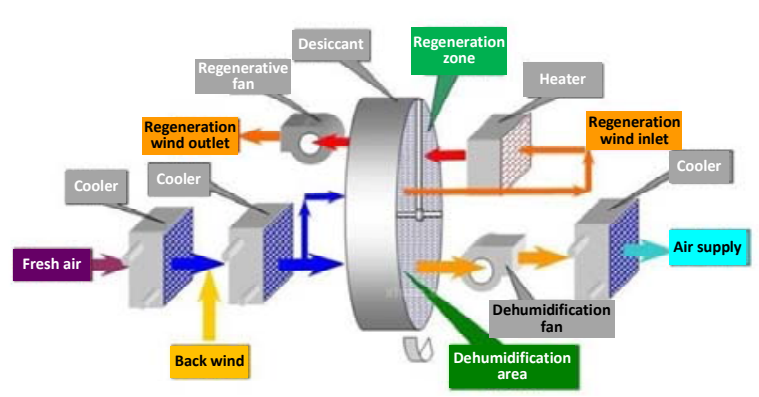

Fig. 7. Schematic diagram of a rotary dehumidifier.

\subsection{Air filtration technology}

Because the enclosed environment in the $500 \mathrm{kV}$ cable tunnel is made of concrete, there is a lot of dust remaining in the tunnel. The dust overflows when the air is circulating, resulting in too much dust in the environment, which not only affects the construction of the cable joints, but also affects the health of construction workers. Air filtration is also essential.

The air filtration technology adopts advanced PWM current-type high-frequency conversion technology and the working mode of voltage stabilization and constant current. It adopts the structure of two-stage electronic dust collector, granular activated carbon filter or cold catalyst filter, which can efficiently adsorb particulates.

The air to be treated is attracted by the motor/fan through the cleanable metal mesh pre-filter to trap largesize particles, and the remaining particles (as small as 0.01 micron) enter the strong electric field (ionized part) to adsorb charges and form charged particles. The charged particles then enter a collection plate composed of a series of equally spaced parallel plates. Each plate carries a charge of the same polarity as the particles, 
thereby repelling the particles from entering the ground electrode plate, achieving the goal of particle collection and air purification.

\subsection{Air volume adjustment technology}

Air conditioning in the tunnel is a necessary means to ensure the fresh air supplement for the constructors in the confined space and maintain the positive pressure in the confined space.

The air volume adjustment technology is realized through electrical control and differential pressure feedback system. When the pressure difference between indoor and outdoor reaches $60 \mathrm{pa}$, the air supply of the system is constant, and the air supply is equal to the sum of the fresh air volume required indoor and the air volume required to maintain indoor cleanliness. When people or equipment enter the room and cause the air leakage to increase, the pressure difference feedback device in the closed environment will feed back the pressure difference alarm signal. The frequency converter controls the increase of the air supply volume until the pressure difference reaches $60 \mathrm{~Pa}$, and then reduces the air supply volume to maintain a positive pressure of $60 \mathrm{~Pa}$.

\section{Performance test of environmental control system for joint installation}

The installation area of the $500 \mathrm{kV}$ cross-linked cable joint was treated with environmental parameters, and temperature test, humidity test and air cleanliness test were carried out. The environmental parameters before and after the use of the environmental control system are shown in Table 2. The air temperature at the working well in the cable tunnel is $34^{\circ} \mathrm{C}$.

Table 2. Test results of environmental parameters for installation area of joints in cable tunnels.

\begin{tabular}{|c|c|c|c|}
\hline \multirow{2}{*}{ Test item } & \multicolumn{3}{|c|}{ Test location } \\
\cline { 2 - 4 } & $\begin{array}{l}20 \mathrm{~m} \text { from } \\
\text { the working } \\
\text { well }\end{array}$ & $\begin{array}{l}300 \mathrm{~m} \text { from } \\
\text { the working } \\
\text { well }\end{array}$ & $\begin{array}{l}1000 \mathrm{~m} \text { from } \\
\text { the working } \\
\text { well }\end{array}$ \\
\hline Before enabling the joint environmental control system \\
\hline temperature & $33^{\circ} \mathrm{C}$ & $31^{\circ} \mathrm{C}$ & $27^{\circ} \mathrm{C}$ \\
\hline humidity & $87 \%$ & $79 \%$ & $75 \%$ \\
\hline $\begin{array}{c}\text { Cleanliness } \\
(1 \mu \mathrm{m})\end{array}$ & $58820 \mathrm{pc} / \mathrm{dm}^{3}$ & $53297 \mathrm{pc} / \mathrm{dm}^{3}$ & $49040 \mathrm{pc} / \mathrm{dm}^{3}$ \\
\hline After enabling the joint environmental control system \\
\hline temperature & $25^{\circ} \mathrm{C}$ & $25^{\circ} \mathrm{C}$ & $25^{\circ} \mathrm{C}$ \\
\hline humidity & $40 \%$ & $40.4 \%$ & $40.5 \%$ \\
\hline $\begin{array}{c}\text { Cleanliness } \\
(1 \mu \mathrm{m})\end{array}$ & $4924 \mathrm{pc} / \mathrm{dm}^{3}$ & $4213 \mathrm{pc} / \mathrm{dm}^{3}$ & $3995 \mathrm{pc} / \mathrm{dm}^{3}$ \\
\hline
\end{tabular}

The test results show that the control system for the installation environment of $500 \mathrm{kV}$ cross-linked cable joints can control the temperature, humidity, and cleanliness of the sealed environment in the joint area.
The temperature of the enclosed area at each location in the cable tunnel is controlled at about $25^{\circ} \mathrm{C}$, the humidity is maintained at about $40 \%$, and the air cleanliness is less than $5000 \mathrm{pc} / \mathrm{dm}^{3}$ (1 $\mu \mathrm{m}$ particles). The system achieves the control objectives of the environmental temperature of the joint installation area not greater than $28^{\circ} \mathrm{C}$, the humidity not greater than $75 \%$, and the cleanliness of the local working area reaches level 9 (the number of $1.0 \mu \mathrm{m}$ dust particles is not greater than $8320 \mathrm{pc} / \mathrm{dm}^{3}$ ).

\section{Conclusion}

(1) The sliced inflatable membrane is easy to process and manufacture, and the installation process is simple, which ensures the airtightness of the joint installation area in the complex cable tunnel and has strong fault repairability.

(2) The integration of refrigeration and air conditioning, air dehumidification, air filtration and air volume adjustment is the key technology to achieve the goal of environmental parameter control in the joint installation area.

(3) The control system of joint installation environment in $500 \mathrm{kV}$ cross-linked cable tunnel provides a stable and clean enclosed environment for the cable joint installation area, which helps to improve the installation quality of high-voltage cable joints in complex construction environments such as cable tunnels, reduces the failure rate of the joints. It is helpful to improve the reliability of high-voltage power cable line operation.

\section{Acknowledgement}

The authors would like to thank project GZHKJXM20160039 (Research and application of key technologies for the construction and operation and maintenance of long-distance large-capacity $500 \mathrm{kV}$ cross-linked cable lines and special tunnels - Issue 1 Research on key technologies for optimal design and construction) for the facilities provided during this research effort.

\section{References}

1. S.W. Ma, B. Zhang, X.K. Yin, et al. Dust prevention measures and practices of UHV GIS instauation. Shandong electric power. J. 58-60, 44(2017)

2. S.B. Huang, M. Huang. Development and application of mobile dust-proof room for installation of $1100 \mathrm{kV}$ GIS expansion project . Electrotechnics Electric. J. 69-71, (2019)

3. X.Y. Guo, G.X. Zhang, X.M. Chen, et al. Selection of installation canopy for middle joint of high voltage cable. Electric Power Equipment Management. J. 34-35, (2019)

4. D.B. Liu, W.Z. Zhu, Y.Q. Liao, et al. Problems of cable joints and design of the flexible cable 
explosion-proof box . Electric Engineering. J. 40-41, 2017)

5. H.S. Zhang, X.X. Gong, Y.H. Zhou, et.al. Research and application of environmental control system in installation area of high voltage cross-linked cable accessories. China Electric (Technical Edition). J. 41-44, 9 (2014)

6. Z.G. Wang, 2010 . Environmental control analysis and countermeasures of $500 \mathrm{kV}$ cable intermediate joints in tunnels. Shanghai Electric Power. J. 301304, 5 (2010),

7. Z.G. Wang, L.J. Zhou, 2010. Construction of $500 \mathrm{kV}$ cable intermediate joint. east china electric power. $\mathrm{J}$. 534-536, 4 (2010.)

8. C.P. Yue. Research on the surface wind pressure characteristics of the light four-slope folding tent. Tianjin University, Tianjin Steel Structure Society. Proceedings of the 16th National Symposium on Modern Structural Engineering. A. (2016)

9. Z.G. Wang. Environmental control analysis and countermeasures for $500 \mathrm{kV}$ cable intermediate joints in tunnels. Shanghai Electric Power. J. 301304, (2010)

10. H. He, S.M. Han, Y.H. Wang, et al. Worksite installation management of $1100 \mathrm{kV}$ GIS for UHVAC southeast-shanxi substation . Power System Technology. J. 11-16, 33 (2009)

11. Z.C. Duan. Schemes on $750 \mathrm{kV}$ GIS installation circumstances condition control in $\pm 800 \mathrm{kV}$ Lingzhou Converter Station . Ningxia Electric Power. J. 26-30, (2016)

12. H.S. Zhang, X.X. Gong, Y.H. Zhou, et al. Research and application of environmental control system in the installation area of high-voltage cross-linked cable accessories . China Electric Power. J. 41-44, (2014) 